NASA Technical Memorandum 103917

L. J. Salerno, P. Kittel, and A. L. Spivak

August 1992

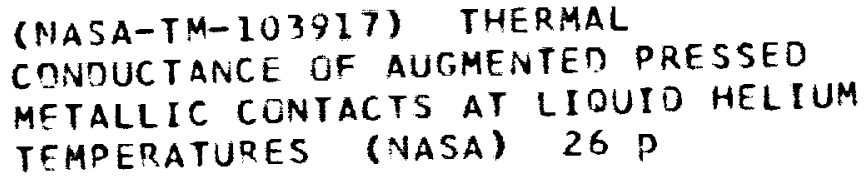

(NASA-TM-103917) THERMAL METALLIC CONTACTS AT LIOUIO HELIUM TEMPERATURES (NASA) 26 P
N92-32474

Unclas

$63 / 34$

0117769 


\section{Thermal Conductance of Augmented Pressed Metallic Contacts at Liquid Helium Temperatures}

L. J. Salerno and P. Kittel, Ames Research Center, Moffett Field, California A. L. Spivak, Trans-Bay Electronics, Richmond, California

August 1992

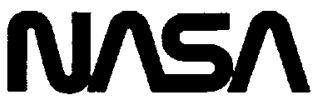

National Aeronautics and

Space Administration 
$-$ 


\title{
Thermal conductance of augmented pressed metallic contacts at liquid helium temperatures
}

\author{
L. J. Salerno, P. Kittel, and A. L. Spivak*
}

NASA Ames Research Center, Moffett Field, CA 94035-1000, USA

*Trans-Bay Electronics, Richmond, Califormia 94084, USA

The thermal conductance of uncoated OFHC copper, 6061-T6 aluminum, free-machining brass, and 304 stainless steel sample pairs which have been augmented with a gold coated 6061-T6 aluminum washer inserted between the contact surfaces has been measured over the temperature range of 1.6 to $6.0 \mathrm{~K}$, with applied forces from $22 \mathrm{~N}$ to $670 \mathrm{~N}$. The contact surfaces of the sample pairs were prepared with a $0.8 \mu \mathrm{m}$ lapped finish, while the finish of the aluminum washer was $0.2 \mu \mathrm{m}$ lapped. The contribution to the overall thermal impedance by the bulk conductance of the aluminum washer was negligible. It was found that addition of the washer offered no significant conductance improvement over an uncoated single contact pair, any benefits from the gold plated washer being used to counteract the addition of two more contact surfaces. Additionally, the thermal conductance of a "combination" aluminum sample pair having one gold coated and one uncoated surface was measured and compared to the washer pair. The ratio of the conductance of the washer pair to half the conductance of the "combination" pair was found to be constant and near unity over the temperature range of the data obtained, within experimental error.

Keywords: pressed contacts; thermal conductance; liquid helium 
The design of space flight missions employing cryogenically cooled instruments requires a knowledge of the thermal conductance of the bolted and pressed contacts between the instruments and their respective refrigeration systems. Previous work ${ }^{1-5}$ has shown that the thermal conductance may be increased significantly by gold coating both contact surfaces. In many instances, due to the size and configuration of the instrument, gold coating of the instrument contact surface or of an entire cold plate may not be feasible. Hence, it has been suggested that gold plated washers placed at the bolted joints between the instrument and its interface may provide a simpler and more cost effective method of augmenting the thermal performance, despite the addition of two more contact interfaces. This paper presents the results of a series of measurements of the thermal conductance of uncoated matched sample pairs fabricated of OFHC copper, 6061-T6 aluminum, free-machining brass, and 304 stainless steel having a gold coated aluminum washer placed between the contact surfaces.

\section{Method}

A detailed description of the apparatus and the experimental method has been presented previously, 1 and will be summarized here. The measurements were made with the lower contact linked to a liquid helium bath held at approximately $1.3 \mathrm{~K}$. The washer is placed in between the two contact surfaces. The conduction path is through an uncoated surface, a gold contact surface, the aluminum washer, another gold contact surface, and an uncoated surface. A range of forces from $22 \mathrm{~N}$ to $670 \mathrm{~N}$ was applied to the contact pair/washer combination, by a rocker arm pulled by a wire. An external motor drive was used to apply the force to the wire. The wire and the rocker arm assembly are thermally anchored to the cold plate, which is immersed in liquid helium. In between the lever and the sample 
pair/washer combination is a stack of insulators. A heater is placed between the insulators and the upper sample. Thermometers are placed in the upper and lower samples, in the upper insulator, and in the cold plate.

The aluminum washers measured $19.0 \mathrm{~mm}$ in diameter and $2.5 \mathrm{~mm}$ in height or $2.5 \mathrm{~mm}$ high. They were prepared by first lapping them to a $0.2 \mu \mathrm{m}$ surface finish. They were then cleaned ultrasonically using 1,1,1 Trichloroethane followed by a reagent grade surfactant (Tergitol), rinsed in deionized water, cleaned ultrasonically in acetone followed by isopropyl alcohol, rinsed in de-ionized water, and blown dry in clean nitrogen gas. Following this procedure, all washers were inspected. In the coating process, the washers were first ion milled. Then a $100 \mathrm{~nm}$ layer of chromium was deposited, followed by $2 \mu \mathrm{m}$ of gold.

Overall dimensions of the sample pairs were $12.7 \mathrm{~mm}$ in diameter and $8.89 \mathrm{~mm}$ in height for the upper sample and $10.2 \mathrm{~mm}$ in diameter and $15.2 \mathrm{~mm}$ in height for the lower sample. All contact surfaces on the sample pairs were lapped to a $0.8 \mu \mathrm{m}$ finish.

\section{Results}

For each sample pair, data were taken at 8 forces $(22,45,11,221,331,441,551$, and $661 \mathrm{~N}$, although the forces were nominally listed at $22,44,112,224,336,448,560$, and $670 \mathrm{~N}), 8$ heater powers in the range from 0 to $10 \mathrm{~mW}$ and for a steady helium bath temperature of approximately 1.3 K. (For the stainless steel pair, power was limited to $2.5 \mathrm{~mW}$ due to the low thermal conductivity of the material.) For each force the resulting data set of upper $\left(T_{h}\right)$ and lower $\left(T_{c}\right)$ sample temperatures, and heater powers ( $Q$ ) was fit to the function 


$$
Q+Q_{o}=\int_{T_{c}}^{T_{h}} \alpha T^{n} d T
$$

where $Q_{0}$ is the parasitic heat flux. The parameters to be fit are $Q_{0}, \alpha$, and $\mathrm{n}_{\text {. }} \mathrm{Q}_{0}$ was $\sim 0.1 \mathrm{~mW}$. The thermal conductance is

$k=\alpha T^{n}$

The fitted thermal conductances are shown in Figures 1-4 for the aluminum, brass, copper, and stainless steel sample pairs. The fitted $\alpha$ and $\mathrm{n}$ are also listed in Table 1 . The errors presented represent the scatter in the data. These errors do not reflect the estimated errors in individual readings which were $\pm 7.3 \mathrm{mK}$ for temperature, $\pm 0.055 \%$ for heat input, and, for force measurements, from $\pm 0.09 \mathrm{~N}$ to $\pm 1.4 \mathrm{~N}$, depending upon sample and applied force.

\section{Discussion}

The conductances of the gold coated aluminum washer sandwich are compared to the conductances of both the previously measured uncoated contacts ${ }^{14}$ and the previously measured gold coated contacts 5 in Figures 5-8. All comparisons are made at the highest applied contact force, $670 \mathrm{~N}$.

From the comparisons in Figures 5-8, it is seen that for the aluminum contact pair, the conductance is virtually unchanged by addition of the gold coated aluminum washer. For the brass sample pair, addition of the washer results in both a degradation of conductance by approximately $1 \mathrm{~mW} / \mathrm{K}$ at $1.6 \mathrm{~K}$, gradually leading to a small improvement in conductance to a maximum of $2.5 \mathrm{~mW} / \mathrm{K}$ at $6.0 \mathrm{~K}$, the crossover occurring at approximately $3.6 \mathrm{~K}$. For the copper sample pair, conductance over the entire temperature range is degraded by addition of the washer, the degradation reaching a maximum of approximately $4.5 \mathrm{~mW} / \mathrm{K}$ at $6.0 \mathrm{~K}$. 
In examining the stainless steel data, it can be seen that the washer data differ from the uncoated data by no more than $0.4 \mathrm{~mW} / \mathrm{K}$, while the gold coated data differs by no more than $0.2 \mathrm{~mW} / \mathrm{K}$. At $6.0 \mathrm{~K}$, the experimental error gives a deviation of $0.1 \mathrm{~mW} / \mathrm{K}$ for the uncoated data , $0.08 \mathrm{~mW} / \mathrm{K}$ for the gold coated data, and $0.04 \mathrm{~mW} / \mathrm{K}$ for the washer data. Therefore, the difference between the uncoated and gold coated data lies within twice the experimental error, while the difference between the uncoated and washer data is roughly four times the experimental error, suggesting that differences may be insignificant. Another uncertainty in the comparison between the augmented, coated, and uncoated stainless steel samples is that the sample pairs were made several years apart, and hence, from different batches of material. Although the data reported here employ a temperature correction to account for the low thermal conductivity of the material, 5 the reported bulk conductivity of 304 stainless steel is dependent upon the particular batch, and any temperature correction made to the data may not be adequate to reflect the true bulk conductivity of the subject batch. A calculation was made comparing the thermal conductance obtained using the uncorrected temperatures with that obtained employing the correction. The result indicated a difference in magnitude of $0.02 \mathrm{~mW} / \mathrm{K}$, or half the experimental error for the washer data, again suggesting that any differences between the stainless steel curves may be insignificant.

The analysis performed here treats the conductance path as a single impedance. This approach is valid, assuming an insignificant contribution to the impedance by the washer. In examining the bulk conductance of the aluminum washer, it was calculated to be over two orders of magnitude higher than the highest contact conductance reported; therefore it was assumed to play a negligible part in the overall contact conductance.

A close look at the thermal path shows that it is greatly constricted at the contacts because the actual contact is made only at a few points, perhaps as low as three. Thus, at the contacts, the heat 
flow is constricted to a small region. This results in an increased temperature gradient in the contact region. It is this increase which is here referred to as the contact conductance. Additionally, the conductance is affected by the presence of oxide layers on the surfaces in contact. Uncoated aluminum, brass, and copper develop an oxide layer quickly after preparation. This layer is a poor thermal conductor. The thermal path between the contacts includes two oxide layers in the region of greatest constriction of the heat flow, thus enhancing the temperature gradient. In the case of stainless steel, however, oxidation occurs much more slowly; therefore its contact conductance is due principally to the constriction effect in the bulk material.

Since the purpose of gold coating the contact surfaces is to prevent oxidation, coated contacts should have only the constriction effect in the base metal, unimpeded by a poorly conducting oxide layer. The dissimilar metals at the interface could affect the local conductivity, however these layers are so thin that their effect should be negligible. Gold, being soft, will deform more readily than the base material. This will increase the actual contact area, decreasing the constriction and increasing the conductance. Again, this layer is so thin that this effect should be negligible. The relative effect of applying the gold layer to the different materials is readily apparent. The gold layer greatly improved the conductance for materials that readily form oxide layers (aluminum, brass, and copper), but did not improve on the material that does not oxidize readily (stainless steel). The reduced conductance of the coated stainless steel over the uncoated contacts may in part be due to the additional layers of material (the coatings) in the region of greatest heat flow constriction.

Introducing a washer between the contact surfaces adds several complications. One is the effect of differential thermal contractions. Such contractions could result in a shear stress at the contact, which in turn might affect the conductance. This problem was avoided by cooling the samples from room temperature with only a light applied force. Furthermore, the first data points were always 
taken with a low applied force, to allow the different materials to independently contract, relieving most of any shear stress. A second complication is that the bulk conductance of the washer is not the same (except for the aluminum sample) as that of the contacts. This may result in thermal mismatch which increases the thermal impedance. A third complication arises from having twice the number of regions of constricted heat flow. Since two of these regions are coated and two are uncoated, it would be expected that the conductance would depend on the sum of these impedances. When thermal impedances are in series, as they are in this case, the impedances simply add. Therefore, the conductance is given by

$\mathbf{k}=\left\{\sum \mathbf{k}_{\mathrm{i}}^{-1}\right\}^{-1}$

where the $\mathrm{k}_{\mathrm{i}}$ are the individual conductances. Thus, the total conductance would be less than that of the uncoated conductance, the effect observed here.

To support this hypothesis, the thermal conductance of the "combination" sample pair was measured. Earlier, the washer conductance had been compared with the sum of the conductance of both a coated and an uncoated sample pair. Figure 9 presents results of this comparison; however, this case is not representative of the actual conditions, thus the "combination" sample was tested. Results are shown in Figure 10. A comparison of half the value of the "combination" conductance with the value of conductance obtained with the washer should show identical results. Figure 11 compares the conductance of half the "combination" case to that of the uncoated, gold coated, and washer cases. In Figure 12, it is demonstrated that the ratio of the thermal conductance for the washer case to half the thermal conductance of the "combination" case is constant, and essentially unity, over the temperature range of the data obtained, within experimental error. An extensive error analysis was performed 
in which the error in the ratio of the thermal conductances was determined. First, it was necessary to determine the error in $\mathbf{k}$, the thermal conductance. Since

$k=\alpha T^{n}$

the error in $k$, as a function of the errors in $\alpha$ and $n$ is given by

$$
\Delta k=\left[\{(\partial k / \partial \alpha) \Delta \alpha\}^{2}+\{(\partial k / \partial n) \Delta n\}^{2}\right]^{1 / 2}
$$

Having obtained this error, the root mean square error for the ratio was calculated at both $1.6 \mathrm{~K}$ and $6.0 \mathrm{~K}$. The error at $1.6 \mathrm{~K}$ was approximately $8 \%$, while at $6.0 \mathrm{~K}$, it was $14.5 \%$.This demonstrates that the thermal conductance of the sample pair having the washer in between is half the conductance of a single contact pair having one gold coated and one uncoated surface.

\section{Conclusions}

The thermal conductance of uncoated OFHC copper, 6061-T6 aluminum, free-machining brass, and 304 stainless steel contacts having a gold coated aluminum washer inserted between the contact surfaces has been measured over the temperature range of 1.6 to $6.0 \mathrm{~K}$, with applied forces from $22 \mathrm{~N}$ to $670 \mathrm{~N}$. The contribution to the overall thermal impedance by the bulk conductance of the aluminum washer was negligible. It was found that addition of the washer offered no significant conductance improvement over an uncoated single contact pair, since any benefit from the use of the gold plated washer was used to counteract the addition of two more contact surfaces. Additionally, the thermal conductance of a "combination" aluminum sample pair having one gold coated and one uncoated surface was measured and compared to the washer pair. The ratio of the conductance of the washer pair to half the conductance of the "combination" pair was found to be constant, and near unity over the temperature range of the data obtained, within experimental error. 


\section{Acknowledgement}

We would like to thank Dave Paananen of Ball Aerospace for his assistance in cleaning and coating the washers.

\section{References}

1 Salemo, L. J., Kittel, P. and Spivak, A. L. Thermal Conductance of Pressed Copper Contacts at Liquid Helium Temperatures, AIAA J, Vol. 22 (1984), p. 1810.

2 Salerno, L. J., Kittel, P. and Spivak, A. L. Thermal Conductance of Pressed OFHC Copper Contacts at Liquid Helium Temperatures, in: Thermal Conductivity 18, Proceedings of the 18th International Thermal Conductivity Conference, Plenum Press (1985), p. 187.

3 Salemo, L. J., Kittel, P., Brooks, W. F., Spivak, A. C. and Marks, W. G., Jr. Thermal Conductance of Pressed Brass Contacts at Liquid Helium Temperatures, Cryogenics, Vol. 26, (1986), 217.

4 Salemo, L. J., Kittel, P., Scherkenbach, F. E. and Spivak, A. L. Thermal Conductance of Pressed Aluminum and Stainless Steel Contacts at Liquid Helium Temperatures, in: Thermal Conductivity 19, Proceedings of the 19th International Thermal Conductivity Conference, Plenum Press (1988), p. 431.

5 Kittel, P., Spivak, A. L. and Salerno, L. J. Thermal Conductance of Gold Plated Metallic Contacts at Liquid Helium Temperatures, to be published in Advances in Cryogenic Engineering, 37 (1992) 
Table 1 Results

$\begin{array}{llll}\text { Force } & \text { Aluminum } & \text { Brass } & \text { Copper }\end{array}$

\begin{tabular}{|c|c|c|c|c|c|c|c|c|}
\hline$(\mathrm{N})$ & $\alpha *$ & $\mathrm{n}$ & $\alpha$ & $\mathbf{n}$ & $\alpha$ & $\mathbf{n}$ & $\alpha$ & $\mathbf{n}$ \\
\hline \multirow[t]{2}{*}{22} & 0.076 & 0.763 & 0.072 & 1.42 & 0.027 & 1.76 & 0.018 & 1.46 \\
\hline & \pm 0.006 & \pm 0.04 & \pm 0.004 & \pm 0.03 & \pm 0.001 & \pm 0.04 & \pm 0.001 & \pm 0.02 \\
\hline \multirow[t]{2}{*}{44} & 0.034 & 1.51 & 0.071 & 1.53 & 0.040 & 1.74 & 0.025 & 1.43 \\
\hline & \pm 0.001 & \pm 0.02 & \pm 0.009 & \pm 0.06 & \pm 0.002 & \pm 0.03 & \pm 0.001 & \pm 0.02 \\
\hline \multirow[t]{2}{*}{112} & 0.061 & 1.82 & 0.081 & 1.80 & 0.071 & 1.94 & 0.073 & 1.08 \\
\hline & \pm 0.003 & \pm 0.03 & \pm 0.005 & \pm 0.04 & \pm 0.004 & \pm 0.03 & \pm 0.002 & \pm 0.02 \\
\hline \multirow[t]{2}{*}{224} & 0.12 & 1.83 & 0.12 & 1.97 & 0.12 & 1.99 & 0.083 & 1.23 \\
\hline & \pm 0.004 & \pm 0.02 & \pm 0.02 & \pm 0.11 & \pm 0.006 & \pm 0.03 & \pm 0.001 & \pm 0.006 \\
\hline \multirow[t]{2}{*}{336} & 0.17 & 1.82 & 0.22 & 1.88 & 0.17 & 1.99 & 0.10 & 1.27 \\
\hline & \pm 0.005 & \pm 0.02 & \pm 0.02 & \pm 0.06 & \pm 0.005 & \pm 0.02 & \pm 0.001 & \pm 0.005 \\
\hline \multirow[t]{2}{*}{448} & 0.20 & 1.85 & 0.26 & 1.92 & 0.21 & 2.00 & 0.12 & 1.27 \\
\hline & \pm 0.004 & \pm 0.01 & \pm 0.02 & \pm 0.06 & \pm 0.006 & \pm 0.02 & \pm 0.001 & \pm 0.004 \\
\hline \multirow[t]{2}{*}{560} & 0.24 & 1.87 & 0.28 & 1.98 & 0.24 & 2.03 & 0.14 & 1.27 \\
\hline & \pm 0.004 & \pm 0.01 & \pm 0.02 & \pm 0.05 & \pm 0.005 & \pm 0.02 & \pm 0.001 & \pm 0.004 \\
\hline \multirow[t]{2}{*}{670} & 0.27 & 1.89 & 0.28 & 2.04 & 0.27 & 2.03 & 0.15 & 1.28 \\
\hline & \pm 0.004 & \pm 0.01 & \pm 0.01 & \pm 0.03 & \pm 0.009 & \pm 0.03 & \pm 0.001 & \pm 0.004 \\
\hline
\end{tabular}

${ }^{*} \alpha$ in units of $\mathrm{mW} / \mathrm{K}^{\mathrm{n}}$ 
Thermal conductance of augmented contacts at LHe temperatures

Figure $10.8 \mu \mathrm{m}$ Aluminum w/Au plated Aluminum Washer

Figure $2 \quad 0.8 \mu \mathrm{m}$ Brass w/Au plated Aluminum Washer

Figure $30.8 \mu \mathrm{m}$ Copper w/Au plated Aluminum Washer

Figure $4 \quad 0.8 \mu \mathrm{m}$ Stainless Steel w/Au plated Aluminum Washer

Figure $5 \quad 0.8 \mu \mathrm{m}$ Aluminum/Au coating/Washer Comparison

Figure $60.8 \mu \mathrm{m}$ Brass/Au coating/Washer Comparison

Figure $70.8 \mu \mathrm{m}$ Copper/Au coating/Washer Comparison

Figure $8 \quad 0.8 \mu \mathrm{m}$ Stainless Steel/Au coating/Washer Comparison

Figure $90.8 \mu \mathrm{m}$ Aluminum/Washer/Sum ( $\mathrm{Au}+$ un)

Figure $10 \quad 0.8 \mu \mathrm{m}$ Aluminum Combination (1 Au coated surface + 1 uncoated)

Figure $110.8 \mu \mathrm{m}$ Aluminum/Au coating/Washer/Au-un Comparison

Figure 12 Aluminum, $0.8 \mu \mathrm{m}$, Ratio of $\mathrm{k}$ Washer to $1 / 2 \mathrm{k}$ Au-un combination 


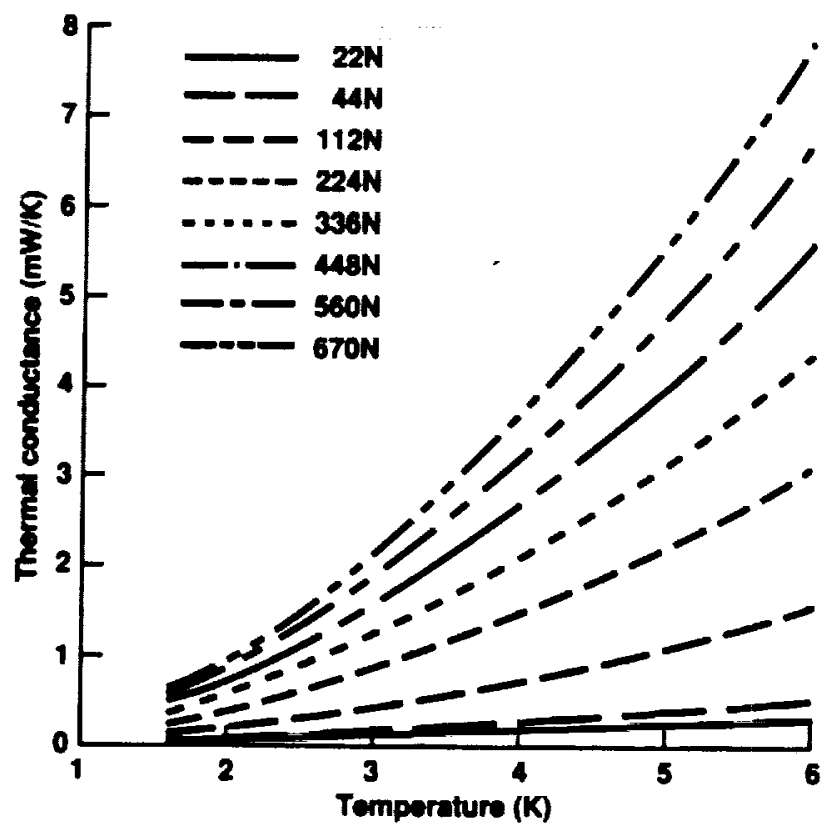

Fig. 1 


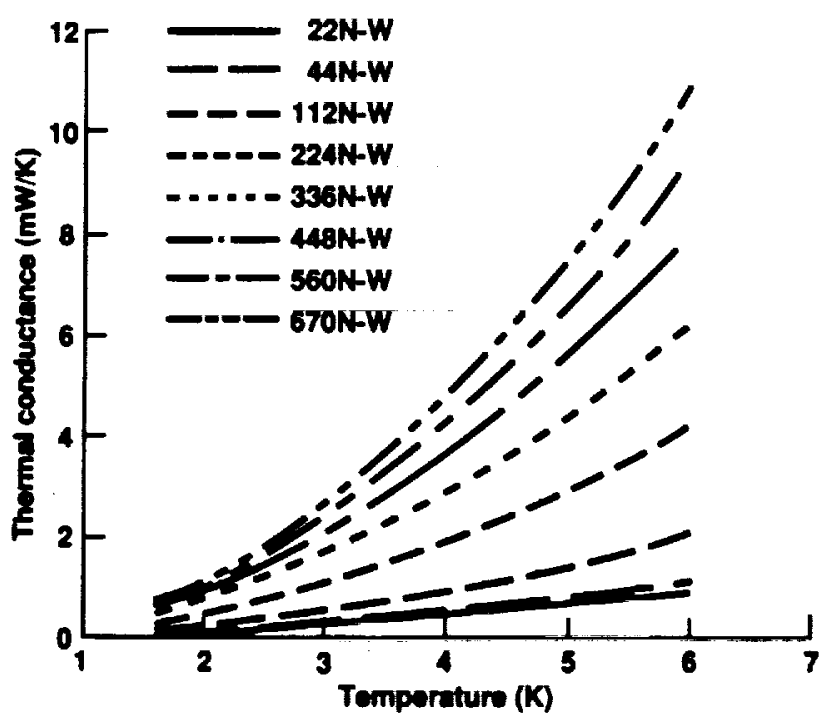

Fig. 2 


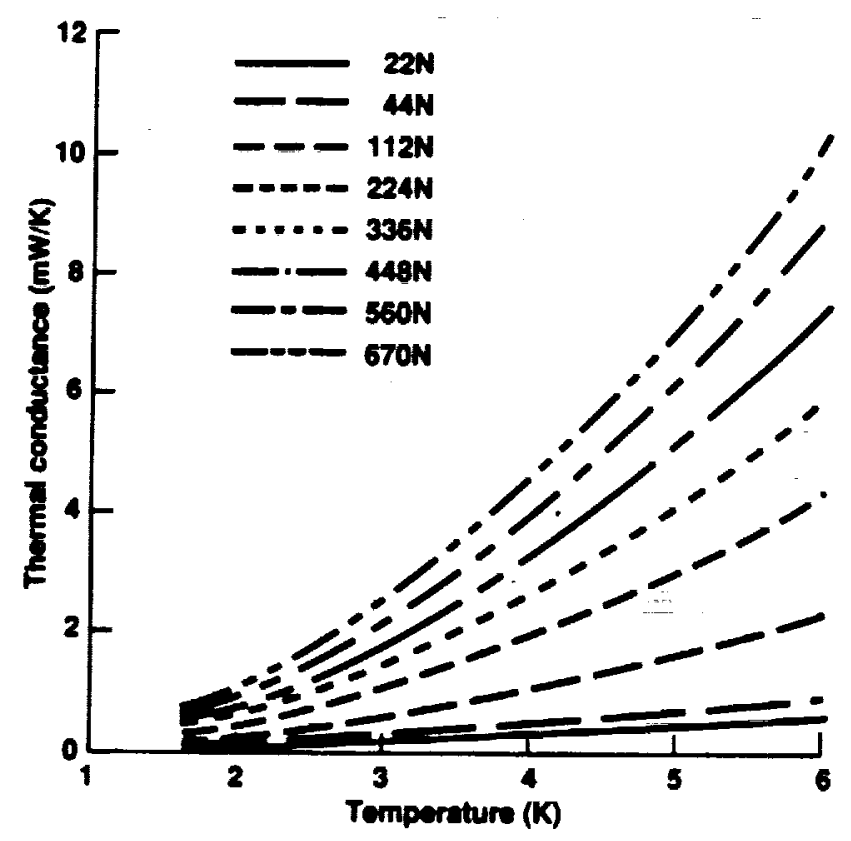

Fig. 3 


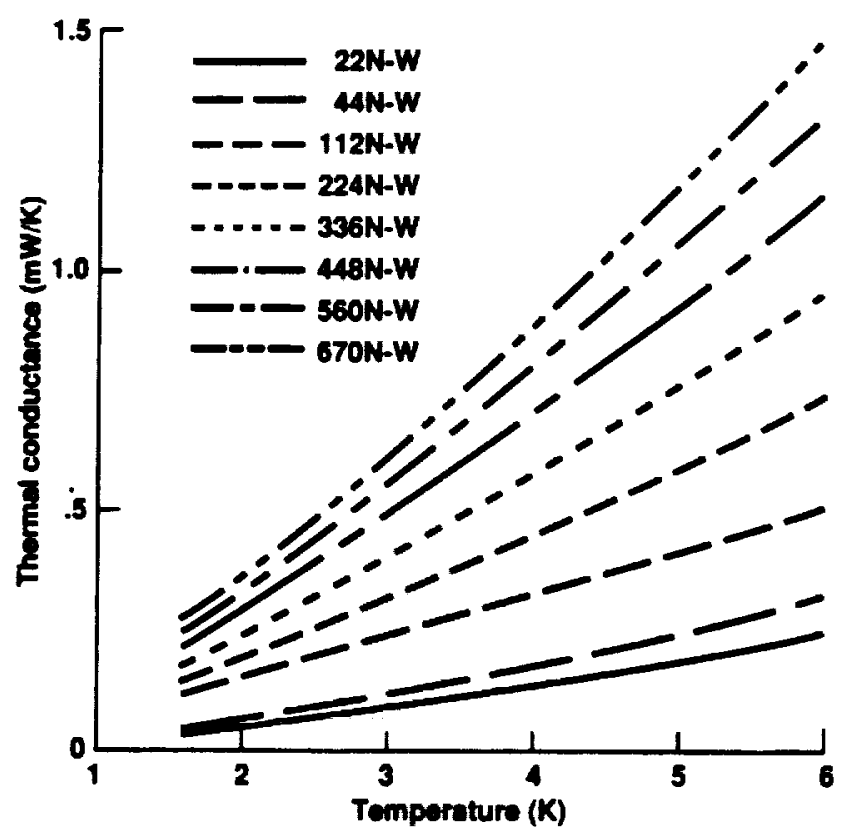

Fig. 4 


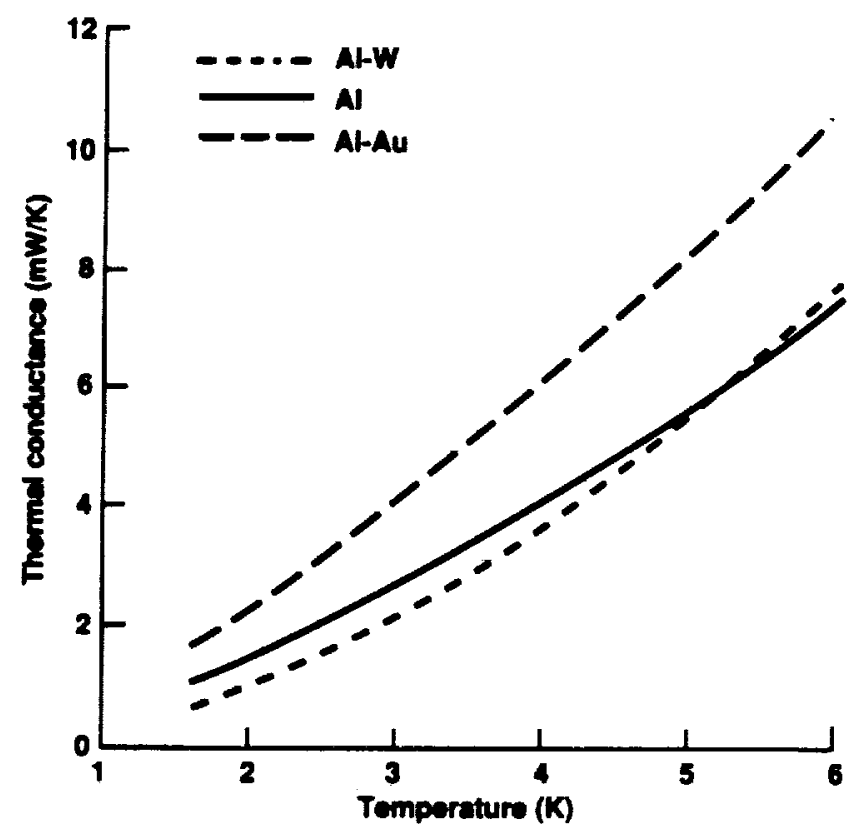

Fig. 5 


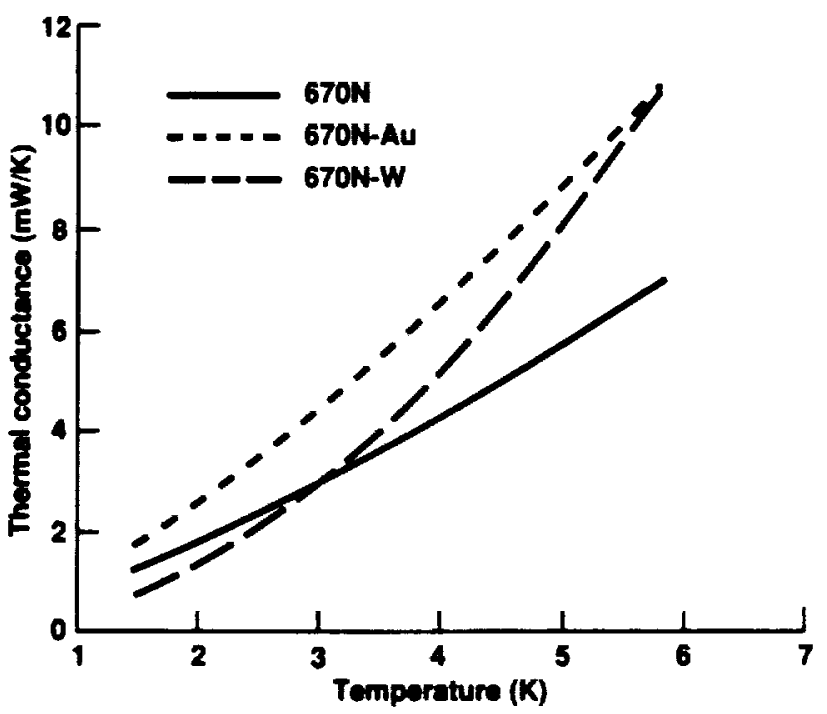

Fig. 6 


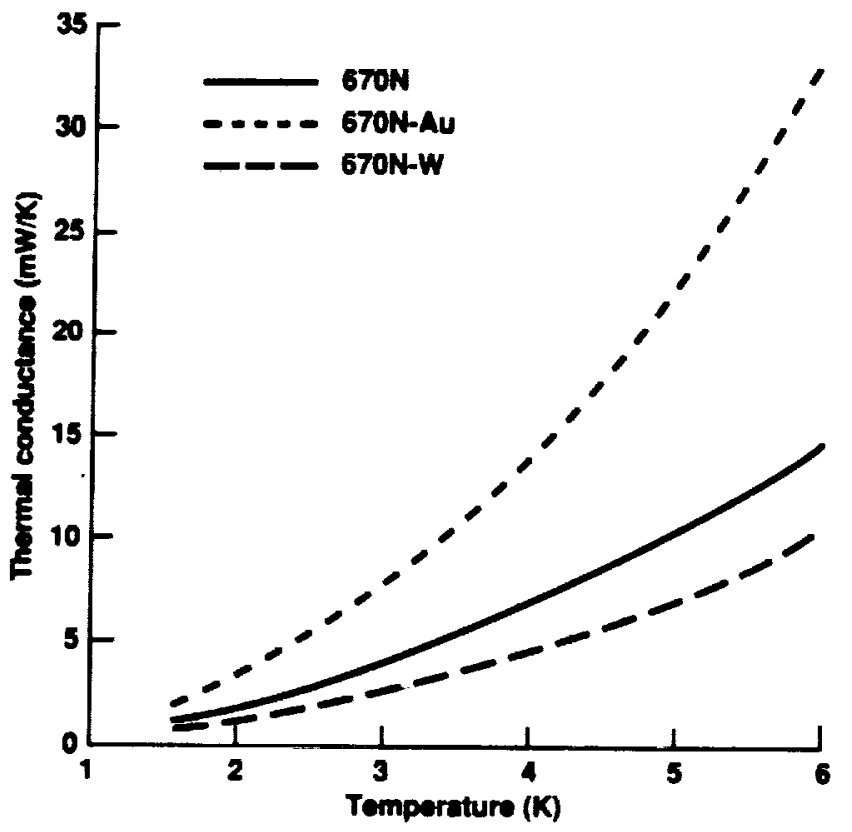

Fig. 7 


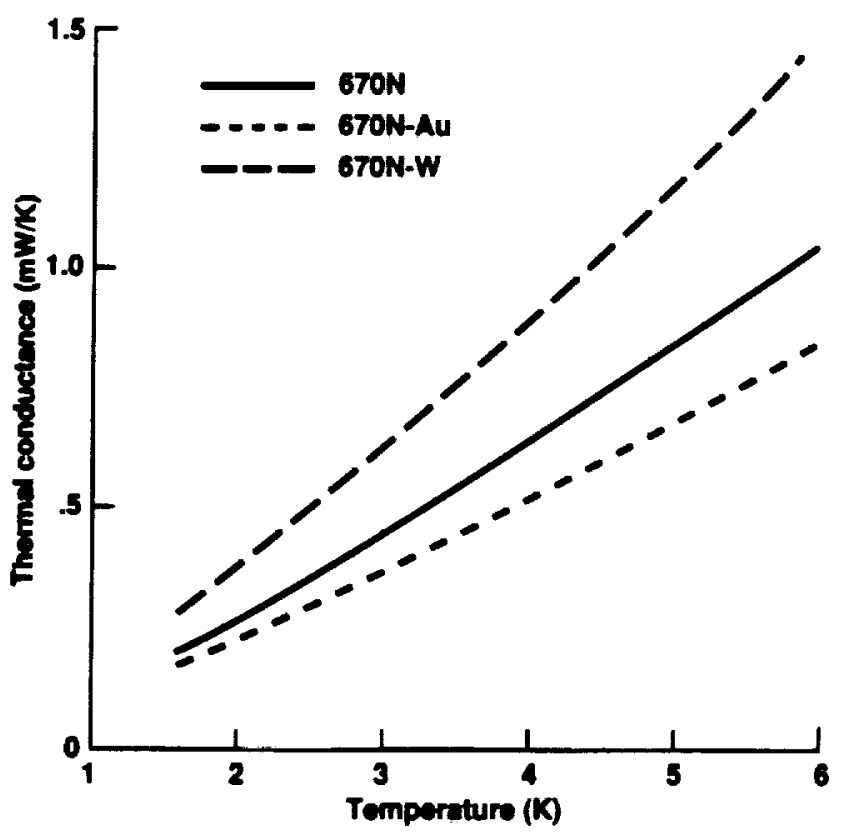

Fig. 8 


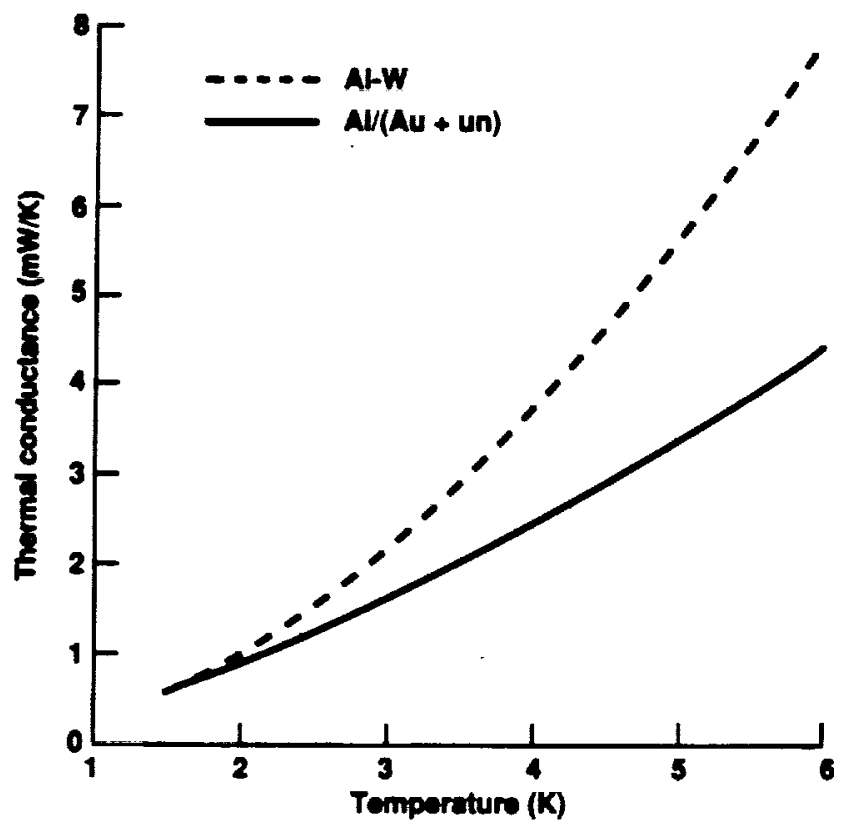

Fig. 9 


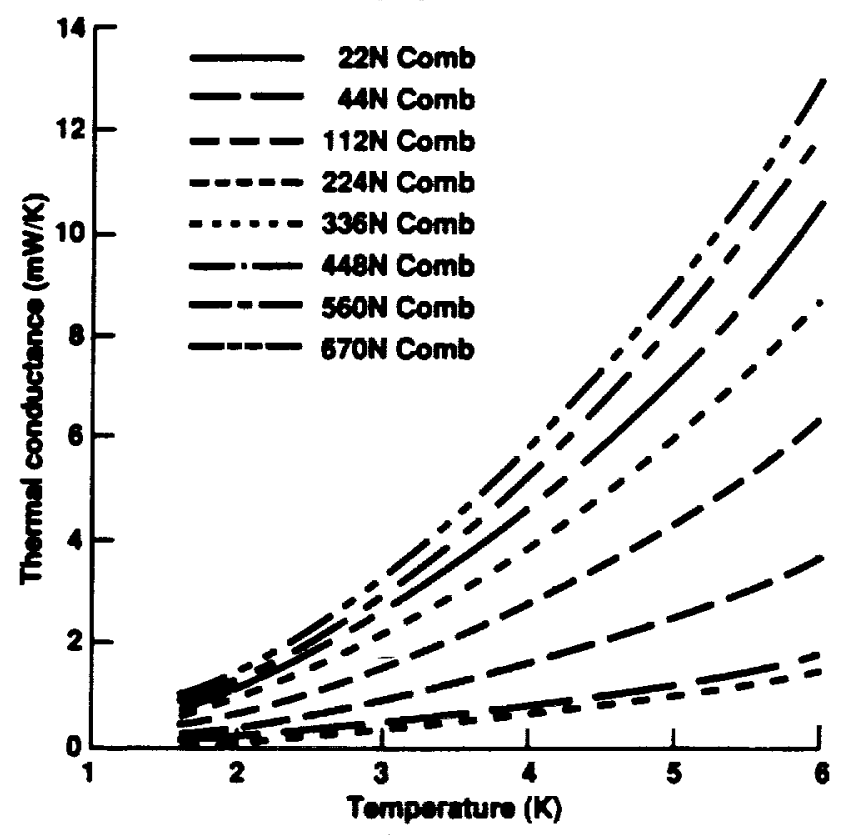

Fig. 10 


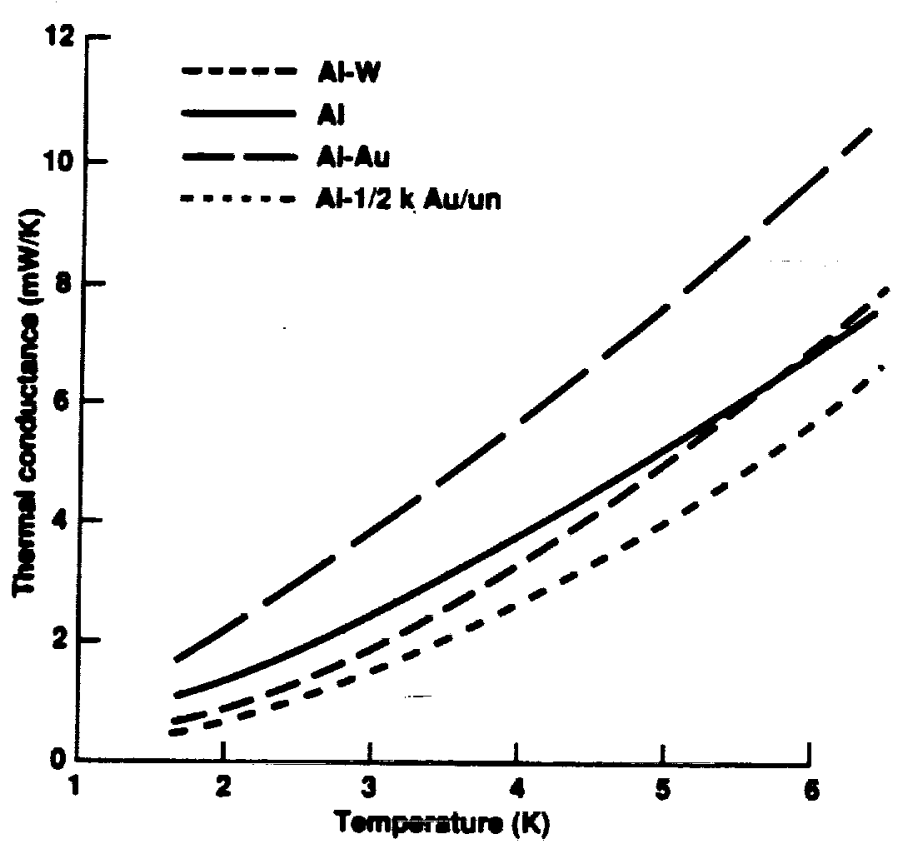

Fig. 11

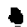




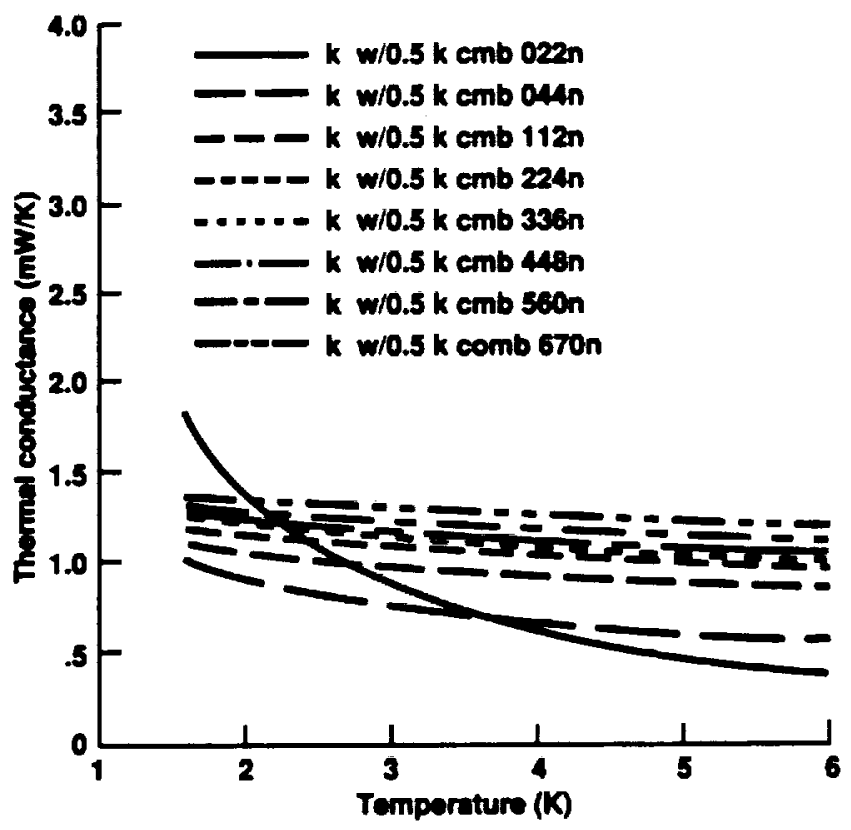

Fig. 12 
$\therefore$ 


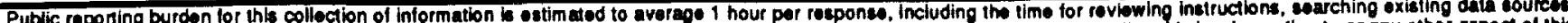
Pulc garhoring and

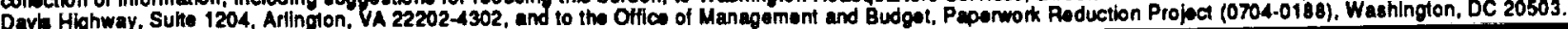

\begin{tabular}{l|l|l} 
1. AGENCY USE ONLY (Leave blank) & 2. REPORT DATE & 3. REPORT TYPE AND DATES COVEREO \\
& August 1992 & Technical Memorandum
\end{tabular}

4. TITLE AND SUBTITLE

Thermal Conductance of Augmented Pressed Contacts of Liquid Helium Temperatures

6. AUTHOR(S)

$590-31-41$

L. J. Salerno, P. Kittel, and A. L. Spivak (Trans-Bay Electronics, Richmond, California 94084)

7. PERForming ORGanization maMe(S) AND ADDRESS(ES)

8. PERFORMING ORGANIZATION REPORT NUMBER

Ames Research Center

Moffett Field, CA 94035-1000

A-92055

9. SPONSORING/MONITORING AGENCY NAME(S) AND ADDRESS(ES)

10. SPONSORING/MONITORING AGENCY REPORT NUMBER

National Aeronautics and Space Administration

Washington, DC 20546-0001

NASA TM-103917

11. SUPPLEMENTARY NOTES

Point of Contact: Lou Salemo, Ames Research Center, MS 244-19, Moffett Field, CA 94035-1000 (415) 604-3189

12a. DISTRIBUTION/AVAILABILITY STATEMENT

12b. DISTAIBUTION CODE

Unclassified - Unlimited

Subject Category 34

13. ABSTAACT (Maximum 200 words)

The thermal conductance of uncoated OFHC copper, 6061-T6 aluminum, free-machining brass, and 304 stainless steel sample pairs which have been augmented with a gold coated 6061-T6 aluminum washer inserted between the contact surfaces has been measured over the temperature range of 1.6 to $6.0 \mathrm{~K}$, with applied forces from $22 \mathrm{~N}$ to $670 \mathrm{~N}$. The contact surfaces of the sample pairs were prepared with a $0.8 \mu \mathrm{m}$ lapped finish, while the finish of the aluminum washer was $0.2 \mu \mathrm{m}$ lapped. The contribution to the overall thermal impedance by the bulk conductance of the aluminum washer was negligible. It was found that addition of the washer offered no significant conductance improvement over an uncoated single contact pair, any benefits from the gold plated washer being used to counteract the addition of two more contact surfaces. Additionally, the thermal conductance of a "combination" aluminum sample pair having one gold coated and one uncoated surface was measured and compared to the washer pair. The ratio of the conductance of the washer pair to half the conductance of the "combination" pair was found to be constant and near unity over the temperature range of the data obtained, within experimental error.

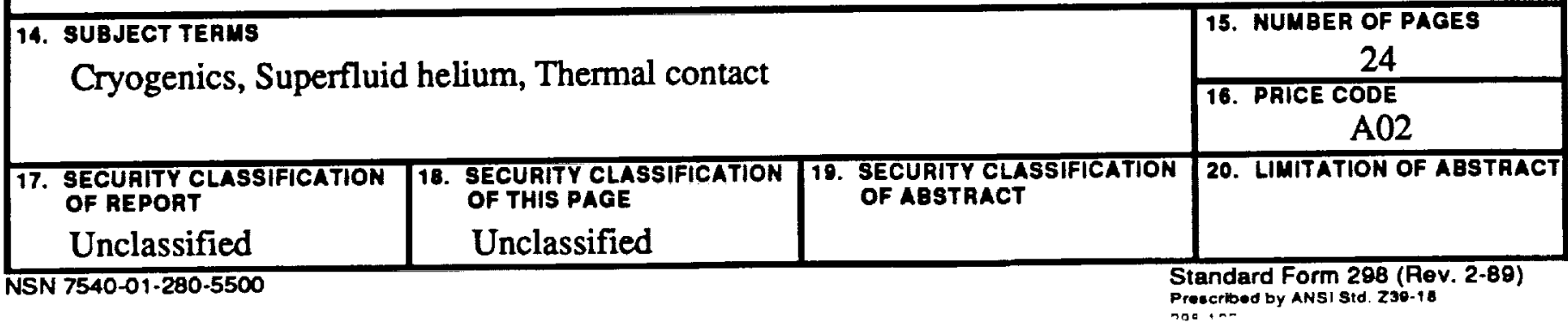




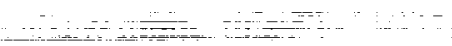

ar

$\therefore-1$

$\checkmark$

5

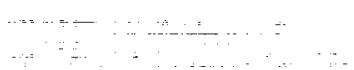

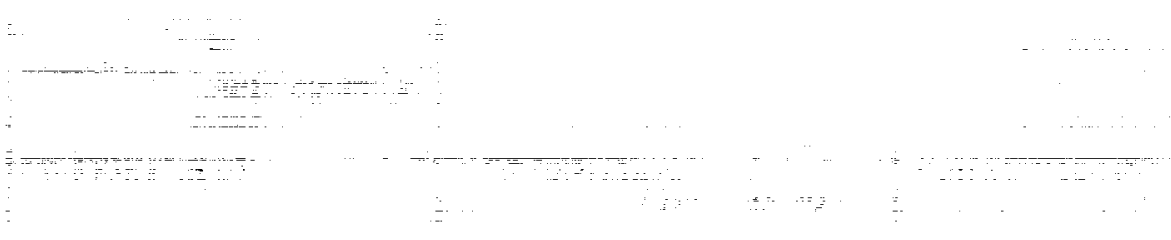

